\title{
Estudo de usuários de informação jurídica: bibliotecário e critérios de qualidade da informação
}

\author{
Genilson Geraldo ${ }^{I}$ \\ Marli Dias de Souza Pinto ${ }^{I I}$

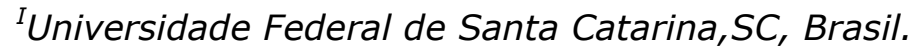 \\ Mestrando em Ciência da Informação. \\ II Professora de Graduação e Pós Graduação(PGCin) - \\ Departamento de Ciências da Informação(DPTcin) /Centro de Ciências \\ da Informação (CED).
}

http://dx.doi.org/10.1590/1981-5344/3334

A informação necessita estar em conformidade com critérios de qualidade precisos e confiáveis, especialmente nos ambientes jurídicos. No Brasil, as publicações crescem diariamente, tais como normas e as mudanças na legislação. Nesse sentido, faz-se necessário conhecer as fontes informacionais e monitorar as mudanças, buscando satisfazer as necessidades dos usuários da informação jurídica. Nesta perspectiva, o estudo objetivou analisar a satisfação dos usuários da informação jurídica no atendimento de suas necessidades informacionais pelo Bibliotecário. Trata-se de uma pesquisa exploratóriadescritiva, cuja coleta de dados se deu a partir da aplicação de um questionário estruturado a profissionais da área do Direito. Constatou-se que o nível de especificidade da informação jurídica é um fator decisivo e de suma importância na atuação profissional e que o nível de confiabilidade das fontes de informação jurídica, reconhecido pela grande maioria dos respondentes, está atrelado à apresentação de autoria e/ou autoridade. Quanto à precisão da informação, evidenciou-se que está ligada diretamente à consistência dos dados informacionais. Enfim, quanto ao reconhecimento e valorização do trabalho do bibliotecário, os pesquisados entendem ser extremamente importantes para o sucesso das assessorias jurídicas. 
Palavras-chave: Estudo de Usuários. Necessidades Informacionais. Informação jurídica. Bibliotecário. Qualidade da Informação.

\section{Study of users of legal information: librarian and quality criteria for information.}

The information need to be in accordance with precise and reliable quality criteria, especially in legal environments. In Brazil, publication grows daily, such as norms and changes in legislation. In this sense, it is necessary to know the information sources and monitor the changes, seeking to satisfy the needs of users of legal information. From this perspective, this study aimed to analyze the satisfaction of users of legal information in meeting their informational needs by the Librarian. This is an exploratory-descriptive research, which data collection was done from the application of a structured questionnaire to law professionals. It was found that the level of specificity of legal information is a decisive factor and of paramount importance in professional practice, and that the level of reliability of the sources of legal information, recognized by the great majority of respondents, is linked to the presentation of authorship and / or authority. As to the accuracy of the information, it has been shown that it is directly linked to the consistency of the informational data. Finally, in the recognition and appreciation of the work of the librarian, the respondents consider it to be extremely important for the success of the legal advisory services.

Keywords: User Study. Informational Needs. Legal information. Librarian. Quality of Information.

Recebido em 29.11.2018 Aceito em 04.02.2019

\section{Introdução}

As bibliotecas jurídicas, assessorias jurídicas e centros de documentação jurídica possuem características bem particulares no desenvolvimento de suas atividades. São voltadas exclusivamente à informação jurídica e à satisfação informacional de seus usuários, com o intuito de subsidiar suas pesquisas, estudos, defesas e causas judiciais. 
Percebe-se que a organização da informação e do conhecimento está presente nas necessidades profissionais das pessoas e das organizações em diferentes áreas. Nas assessorias jurídicas de empresas públicas não é diferente, pois os profissionais de Direito necessitam de acesso rápido e eficiente às informações. Sendo assim, a organização documental e informacional deve envolver o armazenamento e a recuperação de maneira correta e eficiente.

No ambiente jurídico as fontes do direito, são a base de origem da qual nasce o direito, ou seja, os componentes que se utilizam no processo de composição do direito, tais como: as leis, o costume, a jurisprudência, a equidade e a doutrina.

Na Ciência da Informação ao se falar em documento aponta-se os autores Otlet e La Fontaine (1934) como pioneiros neste contexto de discussão, que vai além do suporte físico, perpassando um entendimento de cunho informacional de conteúdo e assunto, um pouco mais a frente Frohmann, em 2004, numa conotação de aspectos institucionais e sociais afirma que o documento é a "materialidade da informação" e que os objetos constituem-se documentos, desde que sejam informativos.

Uma aproximação das noções de documento encontradas na Ciência da Informação e Arquivologia aponta duas direções. Na primeira, o documento é colecionado em função da informatividade de seu conteúdo e os itens recebem um tratamento individualizado. Na Arquivologia, os documentos são acumulados pelo indivíduo ou instituição no decurso de sua vida ou atividade.

Como fica a questão do documento Jurídico conjunto de espécies documentais geradas pelo e/ou para o Direito. Para Nascimento e Guimarães (2004, p. 33-34), o documento jurídico, "revela uma efetiva interface entre as dimensões arquivísticas e biblioteconômicas da informação", em função de "nele residirem aspectos tanto relativo ao binômio proveniência/organicidade quanto ao binômio forma/conteúdo".

A documentação jurídica apresenta muitas dificuldades: "multiplicidade de normas legais sobre a mesma matéria, imperfeições nas alterações, alterações frequentes, variedade de assuntos num mesmo ato e a necessidade constante de atualização". Acrescenta que "a informação jurídica é muito específica/singular quanto ao seu conteúdo e formato (diversidade de tipos de documentos), se comparada com as demais áreas das ciências".

Informação jurídica é de armazenamento constante e permanente, pois mesmo quando revogada, seus preceitos são aplicáveis aos atos jurídicos ocorridos no período de sua vigência. Ressalta, ainda, que mesmo que não seja consultada por um longo tempo, não significa que não tenha valor ou que não seja eficaz.

Porém, destaca-se que o documento jurídico não é apenas um registro de informações históricas para o Direito, mas seu principal meio de efetivação. São, por meio de documentos, que os atos jurídicos são criados, que são estabelecidas as regras de conduta para a sociedade, que são disciplinadas as ações da Administração Pública, 
A informação jurídica é originada fundamentalmente por um tripé informacional distinto: Legislação, Doutrina e Jurisprudência. Legislação é o conjunto normativo que regula a convivência social, elaborada pelo Poder Legislativo dos Municípios, Estados e União; a Doutrina é o conjunto de princípios expostos nas obras de direito, em que se firmam teorias ou se fazem interpretações sobre a ciência jurídica; e a Jurisprudência é a sábia interpretação e aplicação das leis a todos os casos concretos que se submetem a julgamento da justiça, que produz sentenças, no primeiro grau, ou acórdãos e súmulas, nos Tribunais.

Barros (2004, p. 205) afirma que a informação jurídica é "a informação contida numa lei, decreto, decisão, artigo doutrinário, portaria, etc." e se constitui em "base essencial" ao ofício dos aos operadores do Direito. Conclui que "a informação jurídica é apresentada sob três formas básicas, a saber: doutrina, legislação e jurisprudência".

Diante da complexidade que norteia a área da informação jurídica, questiona-se: as necessidades informacionais estão sendo atendidas pelo Bibliotecário dentro dos critérios de qualidade da informação? Sendo assim, a pesquisa, aqui referida, buscou responder esta questão tendo como objetivo principal: analisar a satisfação dos usuários da informação jurídica no atendimento de suas necessidades informacionais pelo Bibliotecário.

O início da indagação, que se desdobrou nesta pesquisa, ocorreu a partir da experiência de atuação em uma assessoria jurídica realizada em empresas públicas, trabalho este que envolveu o auxílio, análise e distribuição de intimações judiciais, petições iniciais, assistência e suporte aos processos jurídicos, busca de documentos e informações como subsídios de defesas judiciais, em prol da empresa. Com isso, estimulouse a realização de um estudo de usuários de informação jurídica em atuação nas empresas públicas.

Oportunizar a atuação do bibliotecário na assessoria, mediação e disseminação da informação jurídica em empresas públicas, é um tema cuja reflexão que se põe também como apoio deste estudo, já que de acordo com Rosa e Crivellari (2007), "[...] é possível inferir que as possibilidades de atuação do Bibliotecário no campo jurídico ainda são pouco conhecidas e que, portanto, fazem-se necessárias mais ações que visem ampliar a oferta de postos neste segmento do mercado de trabalho".

Sendo assim, o tema do artigo se justifica como reflexão sobre o reconhecimento da atuação do bibliotecário na área de informação jurídica. Além disso, visa colaborar com publicações sobre o assunto, tendo em vista que, até o momento da realização deste não foram encontrados muitos estudos com essa temática em bases de dados nacionais e internacionais. Ressalta-se aqui que "o bibliotecário jurídico parece desconhecer os trabalhos de seus pares, e que há necessidade de divulgar mais trabalhos e pesquisas que são realizadas" no âmbito da informação jurídica. (PASSOS, 2004, p. 199). 
Os aspectos metodológicos, quanto aos objetivos do estudo, caracterizam-se como exploratório-descritivo, com aplicação de um questionário aos profissionais da área do Direito.

\section{Aspectos teóricos do estudo}

A presente seção visa subsidiar e dar consistência teórica ao estudo, apresentado os assuntos: Estudos de Usuários, Bibliotecário Jurídico, Informação Jurídica, Qualidade em informação e Necessidade Informacional.

\subsection{Estudos de Usuários}

Os primeiros estudos de usuários tiveram de acordo com Cunha, Amaral e Dantas (2015, p. 31), tiveram início no exterior, e eram conhecidos como "levantamento de bibliotecários". Os autores destacam que, no Brasil, a expressão "Estudos de Usuários" teve origem em meados do século $X X$, e que existem inúmeras definições de estudos de usuários, no âmbito da Biblioteconomia e da Ciência da Informação.

O estudo de usuário da informação é conceituado como o conjunto de conhecimentos, pertencente à área das Ciências da Informação, que tem como objetivo a compreensão e detecção das necessidades do usuário relativamente a informações, com o intuito de integrar o usuário e a informação desejada (COSTA, 2016).

Algumas definições de estudos de usuários da informação destacadas por Cunha, Amaral e Dantas (2015, p. 34), são exemplificados nesta pesquisa relacionando pontos específicos no decorrer dos estudos desenvolvidos nos últimos tempos, tal como, no aspecto: "fonte", explanado no estudo de Saul Hener e Hener (1967 apud CUNHA; AMARAL; DANTAS, 2015), definindo que são estudos sobre as fontes que comunicam mensagens por meio de canais aos receptores, dentro das áreas/disciplinas inter-relacionadas da Bibliografia e Comunicação; "sujeito", abordado por Nice Menezes Figueiredo (1979 apud CUNHA; AMARAL; DANTAS, 2015), explanando investigações que se fazem para saber o que os indivíduos precisam em matéria de informação, ou então, para saber se as necessidades de informação por parte dos usuários de uma biblioteca ou de centro de informação estão sendo satisfeitas de maneira adequada e; "social", retratado por Juan José Calva González (2004 apud CUNHA; AMARAL; DANTAS, 2015), em que referencia a complexa utilização de métodos, técnicas e instrumentos muito diversos, mas todos convergem para o que é pesquisado ou estudado no sujeito chamado usuário, seja ele vinculado a uma unidade de informação, como é mais comum, ou um usuário da informação que pertence a uma comunidade de sujeitos entre os quais existe o fluxo de informação, vinculado ou não a uma unidade de informação.

Cunha, Amaral e Dantas (2015, p. 36), destacam que na perspectiva da Biblioteconomia "o ambiente informacional em destaque é 
a prestação de serviços" em unidades de informação. Deste modo, os estudos de usuários são de grande importância para aqueles que prestam serviços de informação.

Corroborando, Campos, Silva e Pinto (2015) expõem ainda que os "estudos de usuários são empregados, predominantemente, em investigações com profissionais e o público de bibliotecas". E que, para a realização satisfatória desse estudo no desenvolvimento da pesquisa devem "ser observados e empregados elementos que viabilizem o atendimento do objetivo de pesquisa, dentre os quais se encontra o instrumento de coleta de dados". (CAMPOS; SILVA; PINTO, 2015, p. 207).

Nessa perspectiva, Neves e Andrade (2012, p. 56) ratificam a importância do estudo de usuários, expondo que:

[...] são extremamente necessários, não apenas para conhecer e traçar o perfil dos usuários existentes nas unidades informacionais, mas também pela possibilidade de reconhecer e identificar como as atividades devem ser desenvolvidas e administradas para que os níveis de satisfação apresentados pelos usuários sejam sempre elevados.

Dentro das atividades biblioteconômicas desenvolvidas nas unidades de informação, os estudos de usuários são mais frequentes, pois "[...] o sucesso dos produtos e serviços oferecidos por essas instituições depende diretamente da satisfação de pessoas específicas". (CAMPOS; SILVA; PINTO, 2015, p. 207).

A propósito, Alves (1978, apud ANDRETA, 2004, p. 79) expõe o fato de que "exigência de conhecimento dos serviços oferecidos aos usuários tem preocupado algumas bibliotecas que estão procurando medir a qualidade desses serviços e detectar as causas de frustrações dos usuários".

Como o foco do presente estudo é a informação jurídica, a seção a seguir aponta algumas características do profissional bibliotecário em atuação neste contexto.

\subsection{Bibliotecário Jurídico}

A demanda por informação e documentação jurídica é cada vez maior, afinal vivemos um cenário em que o acesso à informação é o grande diferencial competitivo das organizações, entre estas, as jurídicas. Nesse contexto, torna-se fundamental a presença de profissionais de informação que sejam capazes de gerenciar toda a informação jurídica que é produzida diariamente.

No Brasil, segundo o Instituto Brasileiro de Planejamento e Tributação (IBPT), foram criadas 4.960 .610 normas para reger a vida do cidadão brasileiro, entre emendas constitucionais, leis delegadas, complementares e ordinárias, medidas provisórias, decretos e normas complementares, e outros, desde que a atual Constituição Federal (1988) foi promulgada. (INSTITUTO BRASILEIRO DE PLANEJAMENTO E TRIBUTAÇÃO, 2014). Com isso, observa-se que "o setor de informação 
jurídica, talvez, seja o maior produtor de documentos no Brasil" (MIRANDA; D' AMORE; PINTO, 2013, p. 99).

Loureiro (2015, p. 2) discorre que o bibliotecário amplia seu campo profissional a partir do momento em que atua em instituições especializadas, tal como bibliotecário jurídico, e assim, "ao manejar frequentemente a informação jurídica, adquire status de "especialista" dessa informação", podendo exercer o papel de "colaborador" do usuário da informação jurídica, e assim, por conseguinte, se consagrando "intermediador" da informação.

O bibliotecário jurídico é o profissional que "facilita o acesso à informação jurídica de forma ágil e eficiente". Suas competências variam "[...] de acordo com o local em que trabalha ou mesmo em relação à sua especialização". (PASSOS, 2005, p. 32). Entre elas destacam-se medidas descritas por Campos, Silva e Pinto (2015, p. 209), tais como: atualizarse constantemente; conhecer os tipos de documentos jurídicos; saber lidar com as tecnologias; conhecer a terminologia jurídica; estar aberto ao recebimento de sugestões de usuários; trabalhar junto a outros profissionais da área quando necessário.

Entre as habilidades que este profissional deve possuir, destaca-se a capacidade para a pesquisa, organização da informação em diferentes suportes, tratamento da informação e atendimento aos usuários, e gestão de unidades de informação. "O bibliotecário jurídico responsabiliza-se pela direção, coordenação e realização das operações de tratamento e difusão da informação jurídica na unidade onde atua". (CAMPOS; SILVA; PINTO, 2015, p. 209).

Nesse sentido, Passos (2005, p. 33) apresenta a competência do bibliotecário jurídico estabelecida pela American Association of Law Libraries (AALL) em março de 2001, e expõe que o profissional deve:

a) demonstrar forte compromisso com a excelência do serviço ao cliente;

b) reconhecer a diversidade dos clientes e da comunidade;

c) entender e apoiar a cultura e o contexto da biblioteca e das instituições similares;

d) demonstrar conhecimento do sistema legal e da profissão jurídica;

e) entender o contexto socioeconômico e político em que o sistema legal existe;

f) demonstrar conhecimento da teoria da Ciência da Informação e do ciclo documentário;

g) aderir aos princípios éticos da AALL, apoiar e compartilhar dos valores da Biblioteconomia;

h) exibir habilidades de liderança, incluindo pensamento crítico, tomada de risco, independentemente de sua posição na estrutura administrativa; 
i) demonstrar compromisso com o trabalho em grupo para alcançar objetivos comuns;

j) agir dentro da organização para implementar os princípios do conhecimento administrativo;

k) exibir compreensão da importância da multidisciplinaridade dos programas e projetos dentro da organização;

I) dividir conhecimento e perícia com colegas e clientes;

m) dispor de habilidades de comunicação e ser capaz de promover a biblioteca e defender suas necessidades;

n) comunicar-se efetivamente com editores e com a indústria gráfica para promover os interesses da biblioteca;

o) reconhecer o valor da rede profissional e participar ativamente das associações profissionais;

p) perseguir ativamente 0 desenvolvimento pessoal e profissional através da educação continuada. (PASSOS, 2005 p. 9).

Os espaços de atuação para que tais habilidades e práticas de trabalho sejam desempenhadas são variadas, tais como: unidades de informação universitárias, bibliotecas de órgãos governamentais, assessorias jurídicas de empresas públicas e privadas, centros de documentação jurídica e bibliotecas de escritórios de advocacia.

Para se dar mais consistência ao estudo, apresenta-se, a seguir, a informação jurídica na visão de alguns autores.

\subsection{Informação e Documento Jurídico}

Como informação jurídica Miranda, D'Amore e Pinto (2013, p. 9), apontam como originária fundamentalmente por um tripé informacional distinto: Legislação, Doutrina e Jurisprudência:

Legislação é o conjunto normativo que regula a convivência social, elaborada pelo Poder Legislativo dos Municípios, Estados e União; a Doutrina é o conjunto de princípios expostos nas obras de direito, em que se firmam teorias ou se fazem interpretações sobre a ciência jurídica; e a jurisprudência é a sábia interpretação e aplicação das leis a todos os casos concretos que se submetem a julgamento da justiça, que produz sentenças, no primeiro grau, ou acórdãos e súmulas dos Tribunais.

Também os autores Passos e Barros (2009, p. 94) comentam que a informação jurídica "pode ser gerada e recuperada basicamente, em três formas distintas: analítica (por meio de doutrina); normativa (pela legislação) e interpretativa (com emprego da jurisprudência)".

As unidades de informação jurídicas objetivam disseminar a informação jurídica, especificamente na esfera de suas instituições 
mantenedoras, com o fluxo informacional, assim como, auxiliar todos os juristas na aplicação da justiça e até mesmo criar pensamento jurídico.

Estas instituições atuam como principal veículo disseminador desse tipo de informação e que Miranda, D'Amore e Pinto (2013, p. 100) salientam que a "A informação jurídica é elemento imprescindível para que se alcance os objetivos no âmbito jurídico", com isso, as bibliotecas jurídicas devem estar organizadas "visando à satisfação de necessidades informacionais específicas desse público", possuindo uma política de desenvolvimento de suas coleções, como também mecanismos de controles bem estruturados. Para Adeodato (2015), professor do programa de pós-graduação em Direito da Escola Superior da Magistratura de Pernambuco, além da falta de conhecimento dos juristas sobre como pesquisar e apresentar os resultados de suas pesquisas, eles estão geralmente tão envolvidos com os problemas práticos do dia a dia que não dispõem de tempo para estudos e pesquisas mais aprofundadas.

Entre as atividades oferecidas nas unidades de informação jurídica, o serviço de referência e mediação da informação é a mais importante dentro dessas instituições. Barros "O sucesso para encontrar a informação exata, em todos os níveis de busca, depende em grande parte da utilização correta das fontes de informação de que o bibliotecário dispõe". (BARROS, 2004, p. 224). Um meio importante de acesso à informação jurídica, "são as redes de computação, eficientes para consulta a bibliotecas, legislação, jurisprudência e pela imensa gama de informações que possibilitam". (ADEODATO, 2015, p. 7).

No Brasil existem algumas iniciativas públicas que visam à disseminação da informação jurídica. O governo brasileiro disponibiliza várias estratégias de disseminação da informação em ambiente web. Prova disso são as diversas bibliotecas virtuais públicas existentes e que são fontes de informações confiáveis, completas e que contribuem com a promoção da cidadania por meio do acesso a informação ${ }^{1}$.

Outra iniciativa do governo é a disponibilidade do Portal da Transparência do Governo Federal ${ }^{2}$, criado e administrado pela Controladoria Geral da União ${ }^{3}$ (CGU), sendo considerado um dos mais completos e detalhados sites de transparência do mundo.

A Internet hoje representa um dos meios mais baratos e fáceis de comunicação, disseminação e acesso à informação. E assim, benéfica para os profissionais da informação jurídica. Para facilitar o acesso à informação jurídica por meio da Internet, algumas alternativas já foram tomadas, tais como: o acesso à lei, à doutrina e à jurisprudência junto aos sites governamentais (Tribunais, Senado, Câmara dos Deputados Federal, etc.) e também, os sites de revistas jurídicas, que hoje são acessadas mais facilmente que há poucos anos atrás.

A presença de informações jurídicas na Internet, por meio de sites governamentais, como de Tribunais no Brasil, contribuiu de forma importante com esse processo informativo, permitindo o acesso a

\footnotetext{
${ }^{1}$ http://www.acessoainformacao.gov.br/

2 http://www.portaltransparencia.gov.br/

${ }^{3}$ http://www.cgu.gov.br/
} 
decisões judiciais. Essas informações "podem ser divulgadas por meio de processos simplificados de acesso", oferecendo aos usuários, o "acesso de nossos tribunais sem sair de casa ou do escritório". (ZANETTI, 2003, p. 2).

Intensificando isso, Barros (2004, p. 224) expressa que o profissional bibliotecário que atua em unidades de informação jurídica deve ter a consciência de sua função como intermediador ao acesso à informação, "conhecendo as fontes principais para atingir o mais nobre objetivo da Biblioteconomia, que é o de transmitir a informação".

Neste contexto é importante fazer a distinção entre informação e documento jurídico. Informação jurídica para Passos (1994, p. 363) é "toda unidade do conhecimento humano que tem a finalidade de embasar manifestações do pensamento daqueles que lidam com a matéria jurídica". Documento jurídico na perspectiva de Atienza, (1979, p. 19) é a reunião, análise e indexação da doutrina, da legislação, da jurisprudência e de todos os documentos oficiais relativos a atos normativos ou administrativos.

A documentação jurídica, como todos os outros documentos de arquivos especializados (digitais e físicos) apresentam peculiaridades em seu conteúdo, no contexto de produção, em sua finalidade, na forma de criação e formato. Essas características precisam ser consideradas para atingir uma compreensão ampla do que os caracteriza e os diferencia dos demais documentos existentes (TORRES, 2013). Uma observação importante é que embora citados por alguns autores, as três categorias de fontes de documentação jurídica apontadas pela literatura "não abarcam a documentação produzida pelas fontes negociais (contratos, acordos, tratados, convênios, dentre outros), e nem tão pouco as fontes notariais e registrais (certidões, escrituras, testamentos etc.)". (VITORIANO, 2018, p. 14).

Verifica-se que em algumas produções científicas, o termo "documentação jurídica", apresenta quatro acepções diferentes: a) enquanto processo de produzir documentos jurídicos; b) enquanto conjunto de documentos jurídicos produzidos; c) enquanto processos técnicos utilizados na organização de documentos jurídicos e; d) enquanto área de especialização da Ciência da Informação, como afirma Vitoriano (2018).

\subsection{Qualidade da Informação}

$\mathrm{Na}$ história da humanidade a informação passou a ser reconhecida como elemento essencial em todos os segmentos da sociedade. "Tal é sua importância que se manter informado tornou-se indicador incontestável de atualidade e sintonia com o mundo". (DUDZIAK, 2003, p. 23). Nesse sentido, percebe-se que a informação se tornou um grande tesouro ao "Homem". Assim, no decorrer de nossa história, procurou-se aprimorar a qualidade da informação, as formas de armazenamento e preservação e, os meios de disseminação. 
"Com relação à qualidade da informação, é necessário distinguir e discutir os atributos da informação que a qualificam". (AMARAL; SOUSA, 2011, p. 136). Porém, esses atributos podem ser analisados e discutidos de acordo com a realidade específica de cada instituição.

Qualidade é definida pela NBR ISO 8402, como a totalidade das características de uma entidade que lhe confere a capacidade de satisfazer às necessidades explícitas e implícitas. (ASSOCIAÇÃO BRASILEIRA DE NORMAS TÉCNICAS, 1994). E, conforme Calazans (2008) existe um consenso entre os pesquisadores que a qualidade da informação é essencial para a sobrevivência da organização e que "deve ser tratada como um produto que precisa ser definido, medido, analisado e melhorado constantemente para atender as necessidades dos consumidores". (CALAZANS, 2008, p. 30).

Todavia, é perceptível que o uso da informação com qualidade não é novidade entre as organizações informacionais, tendo em vista que "faz parte da própria essência das organizações, mas só nos últimos anos é que se reconheceu a sua importância estratégica". (OLIVEIRA; AMARAL, 1999 , p. 9). Com isso, concretiza-se a visão de Calazans (2008), onde o autor discorre que "a falta de qualidade da informação em uma organização pode proporcionar impactos sociais e no negócio, devendo ser diagnosticada, e esforços devem ser implementados para sua solução". (CALAZANS, 2008, p. 31).

$\mathrm{Na}$ visão de Oliveira e Amaral (1999), dentro das organizações, as decisões dependem e são norteadas pelas informações disponíveis e suas características. "Informação com insuficiente qualidade não produzirá uma decisão adequada que, quando aplicada, produza os resultados esperados". (OLIVEIRA; AMARAL, 1999, p. 9).

Amaral e Sousa (2011, p 134) apresentam uma lista de dimensões da qualidade da informação e seus respectivos atributos para efeitos de qualificação, pontuados por De Sordi (2008, apud AMARAL; SOUSA, 2011), conforme demonstrado no Quadro 1.

Quadro 1 - Dimensões e atributos da informação

\begin{tabular}{|l|l|}
\hline \multicolumn{1}{|c|}{ Dimensões da informação } & \multicolumn{1}{c|}{ Atributos da informação } \\
\hline Acurácia/veracidade & Nível de acurácia; e método para determinação do nível de acurácia. \\
\hline Atualidade/temporalidade & $\begin{array}{l}\text { Data de geração da informação; horário de geração da informação; e } \\
\text { intervalo de tempo entre cada nova geração de informação. }\end{array}$ \\
\hline Disponibilidade & $\begin{array}{l}\text { Meio de acesso à informação; horário de disponibilização da } \\
\text { informação; e tempo decorrido entre a solicitação e o acesso da } \\
\text { informação. }\end{array}$ \\
\hline Confidencialidade/privacidade & Público-alvo; e predileções informacionais do público-alvo. \\
\hline Existência & $\begin{array}{l}\text { Localização do algoritmo para geração da informação; e localização } \\
\text { do armazenamento do conteúdo informacional. }\end{array}$ \\
\hline Abrangência/escopo & Vetores da informação. \\
\hline Integridade & Nível de integridade da informação. \\
\hline Ineditismo/raridade & Disponibilidade de informações idênticas ou similares. \\
\hline Contextualização & Caracterização da informação. \\
\hline Originalidade & Originalidade da Informação. \\
\hline Pertinência/agregação de valor & $\begin{array}{l}\text { Valor potencial da informação } \\
\text { Valor entregue pela informação. }\end{array}$ \\
\hline Identidade & Nome; sinônimos; e autoria \\
\hline Audiência & Frequência de acesso; e duração de tempo de acesso. \\
\hline
\end{tabular}

Fonte: De Sordi (2008, apud AMARAL; SOUSA, 2011, p. 137). 
Deste modo, ao analisar os atributos da qualidade da informação listados por De Sordi (2008, apud AMARAL; SOUSA, 2011) constante do Quadro 1, percebe-se que a existência deles nos cuidados com a qualidade da informação oferecida aos usuários é muito importante para validação e confiabilidade informacional, conforme a opinião de Lau (2008, p. 6), "a quantidade atual de informação requer pessoas que validem e avaliem a informação para comprovar a sua validade".

Lau (2008, p. 6) ressalta ainda sua visão sobre a importância da informação, discorrendo que:

[...] a informação é, em resumo: um elemento vital para a criatividade e a inovação; um recurso fundamental para a aprendizagem e o pensamento humano; um recurso chave para a criação de cidadãos melhor informados; um fator que permite aos cidadãos a obtenção de melhores resultados em suas vidas acadêmicas, em relação com a saúde e o trabalho; um recurso importante para o desenvolvimento socioeconômico.

A preocupação com a qualidade de informação disponibilizada aos usuários de entidades informacionais tem aumentado consideravelmente, sendo assim, o bibliotecário, gestor, mediador e disseminador da informação deve se preocupar em oferecer a seus usuários qualidade na informação entregue, com mecanismos de viabilidade, confiabilidade e integridade da informação.

Reforçando esse pensamento, Sena e Pires (2012, p. 5) dissertam que a "informação precisa ser disponibilizada com qualidade aos usuários, devendo os bibliotecários ter bastante proficiência para desempenharem tal tarefa".

\subsection{Necessidade informacional}

Conforme Cunha, Amaral e Dantas (2015, p. 3), as necessidades de informação são de tipos variados. Os autores exemplificam citando que alguns indivíduos precisam encontrar um documento específico com dados descritos conhecidos ou necessitam encontrar documentos sobre um determinado tema, e outros querem solucionar um problema específico. "Uns necessitam de atualização corrente, enquanto outros precisam de um simples dado ou informação factual".

Também, Neves e Andrade (2012, p. 55) salientam que "esta necessidade também compreende todas as pessoas que, num determinado momento, seu conhecimento se torna insuficiente para elucidar algum impasse, seja de ordem formal ou informal, como algum questionamento em seu cotidiano".

Ainda, para os autores supracitados (p. 56), necessidades podem obter ajuda em diferentes suportes informacionais, mas, independentemente do tipo de suporte ou de tipos de materiais, sejam eles sons, textos, imagens ou dados numéricos, o mais importante nesse contexto informacional é que as necessidades informacionais dos usuários sejam atendidas. 
Entretanto, o bibliotecário mediador na busca de satisfazer as necessidades informacionais de seus usuários, deve possuir habilidades em informação. A definição de "habilidade em informação" mais comumente utilizada e citada é aquela adotada pela Associação Bibliotecária Americana (ALA) e destacada por Lau (2008, p. 7), que diz que "uma pessoa deve ser capaz de reconhecer quando necessita de formação e possuir a habilidade para localizar, avaliar e utilizar efetivamente a informação necessária".

Levando esse contexto para o universo do operador em Direito, para o qual este estudo se direciona, e tendo em vista a disponibilização do profissional bibliotecário jurídico em entidades jurídicas, salienta-se que "pesquisar é quase que sinônimo de estudar, significando, quando muito, uma forma especial de estudo. O advogado que estuda para melhor fundamentar sua argumentação no processo faz pesquisa, sem dúvida". (ADEODATO, 2015, p. 4). Com isso, afirma-se que a informação passou a ser uma fonte vital para as economias mundiais e certamente é o componente básico da educação, sendo um elemento vital para o avanço científico e tecnológico. (LAU, 2008).

Comungando com esta ideia Neves e Andrade (2012, p. 56) apontam que "por meio da necessidade e busca informacional, os estudos de usuários são necessários para a identificação desses agentes, buscando compreender suas necessidades e uso da informação obtida por eles".

E o desenvolvimento da competência de suprir as necessidades desses usuários, e consequentemente, educá-los na busca de informação, deve o bibliotecário, fazer parte da comunidade de aprendizagem e como especialista na gestão da informação, deve ou deveria assumir o papel principal no ensino das habilidades em informação de seus usuários, sendo esta ideia sinalizada por Lau (2008).

\section{Aspectos metodológicos}

A prática de uma metodologia específica nos estudos científicos "é uma postura lógica adotada de investigação, no tratamento dos dados colhidos", isto por meio de procedimentos "que devem ser sistematicamente cumpridos na pesquisa e que, como enfatiza o próprio conceito de Ciência, requerem compatibilidade quer com o objeto, quer com o objetivo". (PASOLD, 2015, p. 71).

Do ponto de vista dos objetivos, esta pesquisa se caracteriza como exploratória descritiva. Para Creswell (2010), a pesquisa descritiva proporciona o levantamento e a identificação de tendências, de atitudes ou de opiniões de uma população, a partir de uma amostra desta: utilizase de questionário ou de entrevistas para a coleta de dados e assim, proporciona uma maior familiarização com uma dada temática, por isso também é pesquisa exploratória.

$O$ instrumento de coleta de dados utilizado foi um questionário estruturado, aplicado a 16 profissionais da área do Direito de uma empresa pública, situada em Santa Catarina, sendo 12 advogados e quatro assistentes jurídicos. 
A abordagem da pesquisa é de caráter qualitativo e quantitativo para extração dos resultados da pesquisa. A abordagem qualitativa envolve duas atividades:

Em primeiro lugar, desenvolver uma consciência dos tipos de dados que podem ser examinados e como eles podem ser descritos e explicados; em segundo, desenvolver uma série de atividades práticas adequadas aos tipos de dados e às grandes quantidades deles devem ser examinadas. (GIBBS, 2009, p. 17).

Para Mozzato e Grzybovski (2011, p. 737), o conhecimento dos diversos métodos de análise de dados existentes "torna-se indispensável para que o pesquisador tenha condições de realizar a escolha mais adequada ao que se propõe estudar, visando ao avanço na temática e, consequentemente, no campo de estudo".

Esta pesquisa é também bibliográfica, na qual foram descobertos e utilizados artigos científicos, dissertações, teses e livros de diferentes autores relacionados à temática, como apoio para a fundamentação conceitual.

Em prosseguimento, apresenta-se a análise dos dados e a interpretação dos resultados da pesquisa.

\section{Análise dos dados e interpretação dos resultados}

Os dados da pesquisa foram obtidos por meio do questionário composto de 09 questões distribuídas da seguinte maneira: sobre perfil do respondente; qualidade da informação jurídica (consistência, confiabilidade e especificidade) e atuação do bibliotecário na área e, uma questão reservada para sugestões/considerações.

\subsection{Perfil}

Os respondentes da pesquisa foram compostos por uma amostra de 16 profissionais do Direito atuante em empresas públicas de Santa Catarina. Com relação à faixa etária: (56\%) têm entre 31 a 50 anos; $(31,5 \%) 30$ a 21 anos e, $(12,5 \%)$ não responderam à questão. Quanto à atuação profissional na área do Direito: (56\%) atuam na área de 20 a 11 anos e, (44\%) possuem entre 10 e quatro anos de atuação na área.

\subsection{Qualidade da Informação Jurídica}

Nesta subseção do estudo apontam-se as respostas sobre a qualidade com foco na consistência, confiabilidade e especificidade das informações jurídicas.

\section{a) A consistência das informações jurídicas}

A maioria das respostas apontou que a disponibilização de informações consistentes assegura a qualidade $e$ veracidade da informação, dando credibilidade para embasar a teoria estudada, 
definindo estratégias no bom entendimento dos assuntos atrelados, sendo assim uma importante arma de fundamentação, caso contrário, pode-se perder uma ação ou dar uma orientação equivocada.

Três respostas sinalizam que a consistência das informações jurídicas é indispensável para aperfeiçoar a qualidade da assessoria jurídica técnica e a prestação jurisdicional, possibilitando uma segurança jurídica necessária, desenvolvendo assim, de forma ética e correta a profissão.

Deste modo, as respostas obtidas, nesta questão estão amparadas, pelo que sinaliza Adeotado (2015), além da falta de conhecimento dos juristas sobre como pesquisar e como apresentar os resultados de suas pesquisas, eles estão geralmente tão envolvidos com os problemas práticos do dia-a-dia que não dispõem de tempo para estudos e pesquisas mais aprofundadas.

\section{b) Confiabilidade das informações jurídicas}

Com relação à confiabilidade das informações jurídicas maioria significativa das respostas versou que estas são primordiais para a atuação do profissional de Direito, que o acesso às informações jurídicas necessita de uma análise criteriosa das fontes de informação.

Também houve respostas que apontam que a confiança no corpo jurídico, na empresa pública, evita retrabalho, ou seja, para saber filtrar informações jurídicas de confiabilidade é preciso contar com uma fonte de repositório atestado e rastreável.

\section{c) Especificidade da Informação Jurídica}

O Direito é composto de vários ramos com procedimentos e regras diferentes, cada qual de acordo com a sua matéria, que constantemente são atualizadas por meio de doutrinas, jurisprudências e legislações que se modificam de acordo com o tempo e costumes de cada realidade, 0 operador de Direito depara-se com uma infinidade de informações jurídicas que são inerentes à amplitude da área.

Adeotado (2015, p. 4) auxilia nos argumentos anteriormente apresentados quando afirma que "pesquisar é quase sinônimo de estudar, significando, quando muito, uma forma especial de estudo". "O advogado que estuda para melhor fundamentar sua argumentação no processo faz pesquisa, sem dúvida".

Nas respostas obtidas sobre o nível de especificidade estes em sua maioria referem-se à necessidade de endereçar as informações para áreas ou temas específicos, que também é importante o conhecimento da doutrina e da jurisprudência dos tribunais, para que possa oferecer à jurisdicional adequada assessoria técnica, alcançando o resultado processual. Complementando as respostas sinalizaram que 0 bom desenvolvimento da atividade jurídica é quanto maior a especificidade da informação mais útil será para o profissional do Direito. 


\subsection{O Bibliotecário Jurídico}

Para analisar a prestação de serviços do bibliotecário à assessoria jurídica utilizaram-se as competências multifacetadas estabelecidas pela American Association of Law Libraries (AALL) e interpretadas/direcionadas para informação jurídica adaptado de Passos (2005).

O resultado, na visão dos respondentes, foi analisado a partir de escala Likert de 1 a 5, sendo: 5 muito importante; 4 importante; 3 importância regular 2 sem importância e 1 desconheço.

a) prover e personalizar serviços de referência sobre tópicos jurídicos e também em relevantes tópicos não jurídicos: constatou-se que: (50\%) acreditam ser muito importante; $(43,75 \%)$ importante e $(6,25 \%)$ desconhecem;

b) avaliar a qualidade, autenticidade, acuracidade das fontes informacionais: para $(62,5 \%)$ são muito importante; $(31,25 \%)$ importante; $(6,25 \%)$ de importância regular.

c) auxiliar o advogado com as pesquisas jurídicas utilizando tanto os recursos impressos quanto eletrônicos: comprovou-se que $(50 \%)$ afirmam ser muito importante; (31,25\%) importante e respectivamente $(18,75 \%)$ acreditam ser de importância regular.

d) agregar conteúdo a variedade de recursos e sintetizar a informação: notou-se que $(56,25 \%)$ revelam ser muito importante; $(12,5 \%)$ importante $(25 \%)$ importância regular; e; $(6,25)$ sem importância;

e) oferecer e/ou criar instrumentos de pesquisa e bibliográficos em Direito e tópicos correlatos: apurou-se que $(68,75 \%)$ alegam ser muito importante e $(31,25 \%)$ importante;

f) conhecer e oferecer as ferramentas de que o profissional da informação dispõe para montar estratégias de busca que visam a garantir alto índice de precisão no resultado das pesquisas: constatou-se que $(100 \%)$ dos profissionais respondentes afirmam ser muito importante;

g) monitorar as tendências em áreas específicas do Direito: descobriu-se que $(43,75 \%)$ declaram ser muito importante; $(25 \%)$ importante; $(25 \%)$ importante regular e $(6,25 \%)$ sem importância;

h) sempre que possível, complementar uma informação com outra, agregando valor ao serviço. Por exemplo, ao informar a publicação de uma nova lei que altera dispositivo da CLT, informar também a redação anterior da norma, conferindo agilidade à pesquisa: os respondentes expõem considerar 
(50\%) muito importante; $(18,75 \%)$ importante $(25 \%)$ de importância regular; e $(6,25 \%)$ desconhecem;

i) selecionar artigos de periódicos que comentam as atualizações legislativas e encaminhá-los aos advogados: $(50 \%)$ afirmam ser muito importante; $(37,5 \%)$ importante e $(12,5 \%)$ de importância regular;

j) promover a divulgação da produção intelectual interna do Orgão, dando destaque à iniciativa e estimulando a geração de novos conhecimentos: $(43,75 \%)$ pensam em ser muito importante; sendo com a mesma proporção (43,75\%) considera importante e $(12,5 \%)$ de importância regular.

De acordo com as respostas referente às competências sobre a prestação de serviços do bibliotecário na área jurídica, os respondentes de forma unânime sinalizaram que estes oferecem e ou criam instrumentos de pesquisa e bibliográficos em Direito, disponibilizam estratégias de busca visando garantir alto índice de precisão no resultado da pesquisa.

$\mathrm{Em}$ suas respostas a maioria entende que o Bibliotecário, personaliza serviços de referência sobre tópicos jurídicos, avaliam a qualidade, autenticidade, acuracidade das fontes informacionais, auxiliam os advogados com as pesquisas jurídicas utilizando fontes de informação que além de permitirem confiabilidade nos serviços oferecidos, atuam constantemente com a informação, e assim, facilitam a gestão da informação sendo estes de suma importância para validação, organização e interpretações das informações.

Sinalaram, também, que, a pertinência e a preocupação do bibliotecário, com a consistência e confiabilidade das informações jurídica, sempre vem agregar de forma simples e fácil a utilização das questões jurídicas, adequando as fontes existentes e localizando-as com rapidez e segurança. Estas respostas são amparadas pelos autores Campos, Silva e Pinto (2015) referindo-se ao assunto de que se deve "[...] estar aberto ao recebimento de sugestões de usuários; trabalhar junto a outros profissionais da área quando necessário".

Nesse sentido, destaca-se a afirmativa de Lau (2008, p. 6) quando menciona que "a quantidade atual de informação requer pessoas que validem e avaliem a informação para comprovar a sua validade".

\section{Considerações finais}

Estudos de Usuários em unidades de informação especializadas mostra-se relevante no universo de informação, no presente artigo objetivou-se analisar a satisfação dos usuários da informação jurídica no atendimento de suas necessidades informacionais pelo Bibliotecário e, este foi cumprido integralmente.

Entidades que administram a informação estão frequentemente atualizando seus serviços e desenvolvendo seus produtos informacionais com novas técnicas de armazenamento, atendimento ao usuário e 
disseminação da informação, tendo em vista, o crescente volume de informações e documentos jurídicos produzido no Brasil, conforme exposto nesta pesquisa.

Neste contexto, a participação do bibliotecário nessas unidades de informação propicia um melhor desenvolvimento destas instituições. De acordo com alguns autores, tal como, Passos (2009); Miranda, D'Amore e Pinto (2013), o bibliotecário jurídico é um profissional que facilita o acesso à informação jurídica de forma ágil e eficiente. Suas competências variam de acordo com o local que trabalham (universidade, bibliotecas governamentais, escritórios de advocacia).

Entretanto, conforme evidenciado, a produção científica sobre esta temática ainda é pequena $e$, seu reconhecimento ainda não se consolidou, tornando imprescindível que estes profissionais divulguem e disseminem seus conhecimentos e experiências aos pares, contribuindo para 0 crescimento profissional e científico de toda classe.

Os questionários respondidos pelos profissionais da informação mostraram que os níveis de especificidade da informação jurídica é um instrumento decisivo e de suma importância na atuação profissional destes respondentes, tendo em vista, que quanto maior a especificidade da informação mais útil será ao profissional. Em relação às percepções destes profissionais quanto à consistência das fontes de informação jurídica, relatou-se que são atrelados à cobertura da fonte e validade do conteúdo oferecido e, consequentemente, a coerência na apresentação do conteúdo informacional e a disponibilização de informações filtradas e/ou com agregação de valores.

Quanto à relação ao nível de confiabilidade das fontes de informação jurídica, constatou-se que a grande maioria dos respondentes acredita estar atrelada à apresentação de autoria e/ou autoridade identificada nos documentos, e ainda com a disponibilização das informações/documentos originais. Evidenciou-se que para muitos profissionais que participaram da pesquisa, o nível de precisão da informação está ligado à consistência nos dados informacionais e também à disponibilização das informações/documentos originais e ainda, o acesso a informações filtradas e/ou com agregação de valor.

Um fato averiguado na pesquisa e que merece destaque é o comportamento dos advogados respondentes em relação ao uso da informação jurídica, em que ficou estabelecido que é o instrumento principal para realização do trabalho desses profissionais. Sendo assim, conforme exposto pelos respondentes, a informação jurídica é um instrumento indispensável para aperfeiçoar a qualidade da assessoria jurídica técnica e a prestação jurisdicional, possibilitando uma segurança jurídica necessária e desenvolvendo a profissão de forma ética e correta.

Outro aspecto contemplado na pesquisa diz respeito ao reconhecimento e valorização do trabalho dos bibliotecários a estes profissionais. Ficou evidenciado que muitos profissionais reconhecem, valorizam e acreditam ser extremamente importante o trabalho do bibliotecário para o sucesso das assessorias jurídicas. As respostas obtidas levam à conclusão de que o Bibliotecário é reconhecido, no campo 
jurídico, exatamente pela formação que obteve e que o qualifica para o exercício da profissão.

Finalizando, expõe-se o objetivo do estudo de analisar a satisfação dos usuários da informação jurídica no atendimento de suas necessidades informacionais pelo Bibliotecário, foi atendido $e$, que o Bibliotecário na entidade estudada tem reconhecimento de seus atributos profissionais em disponibilizar informações com qualidade para área do Direito.

\section{Referências}

ADEODATO, João Maurício. Bases para uma metodologia da pesquisa em direito. 2011. Disponível em: http://www.egov.ufsc.br/portal/conteudo/bases-para-uma-metodologiada-pesquisa-em-direito. Acesso em: 9 jun. 2017.

AMARAL, Sueli Angélica do; SOUSA, Antonio José Figueiredo Peva de. Qualidade da informação e intuição na tomada de decisão organizacional. Perspectivas em Ciência da Informação, Belo Horizonte, v. 16, n. 1, p.133-146, jan. 2011. Disponível em:

http://portaldeperiodicos.eci.ufmg.br/index.php/pci/article/view/1015.

Acesso em: 9 jun. 2017.

ANDRETA, Cássio Adriano. Legislação como assunto: uma proposta de extensão para a classificação decimal de direito. In: PASSOS, Edilenice (Org.). Informação jurídica: teoria e prática. Brasília: Thesaurus, 2004. Cap. 3. p. 79-124.

ASSOCIAÇÃO BRASILEIRA DE NORMAS TÉCNICAS (ABNT). NBR ISO 8402: 1994: gestão da qualidade e garantia da qualidade: terminologia. Disponível em: http://www.ecnsoft.net/wp-content/plugins/downloadsmanager/upload/ISO IEC 9126 - Parte Escrita.doc. Acesso em: 9 jun. 2017.

ATIENZA, C. A. Documentação jurídica: introdução à análise e indexação de atos legais. Rio de Janeiro: Achiamé, 1979.

BARROS, Lucivaldo. Fontes de informação jurídica. In: PASSOS, Edilenice (Org.). Informação jurídica: teoria e prática. Brasília: Thesaurus, 2004. Cap. 9. p. 201-225.

CALAZANS, Angélica Toffano Seidel. Qualidade da informação: conceitos e aplicações. Transinformação, Campinas, v. 20, n. 1, p. 29-45, jan. 2008. Disponível em: http://periodicos.puccampinas.edu.br/seer/index.php/transinfo/article/view/539. Acesso em: 9 jun. 2017.

CAMPOS, Cirlei Oraci Dias de; SILVA, Emanoel Quartiero da; PINTO, Marli Dias de Souza. A satisfação de usuários da informação jurídica: estudo na biblioteca da OAB/SC. Perspectivas em Ciência da Informação, Belo Horizonte, v. 20, n. 3, p. 200-217, jul. 2015. Disponível em: 
http://portaldeperiodicos.eci.ufmg.br/index.php/pci/article/view/2366. Acesso em: 9 jun. 2017.

COSTA, Maria de Fátima Oliveira. Estudos de usuários da informação: ensino e aprendizagem no Brasil. Fortaleza: UFC, 2016. 246 p.

CRESWELL, John W. Projeto de pesquisa: métodos qualitativo, quantitativo e misto. 3. ed. Porto Alegre: Artmed, 2010.

CUNHA, Murilo Bastos da; AMARAL, Sueli Angélica do; DANTAS, Edmundo Brandão. Manual de estudos de usuários da Informação. São Paulo: Atlas, 2015. 448 p.

DUDZIAK, Elizabeth Adriana. Information literacy: princípios, filosofia e prática. Ciência da Informação, Brasília, v. 32, n. 1, p. 23-35, jan. 2003. Disponível em: http://revista.ibict.br/ciinf/article/view/1016. Acesso em: 9 jun. 2017.

FLICK, Ewe. Introdução à pesquisa qualitativa. 3.ed. Porto Alegre: Artmed, 2009. 405p.

GIBBS, Graham. Análise de dados qualitativos. Porto Alegre: Artmed, 2009. 198p.

INSTITUTO BRASILEIRO DE PLANEJAMENTO E TRIBUTAÇÃO (IBPT). Brasil cria, em média, 46 novas regras de tributos a cada dia útil. 2014. Disponível em: http://www.ibpt.com.br/noticia/1951/Brasil-cria-emmedia-46-novas-regras-de-tributos-a-cada-dia-util. Acesso em: 9 jun. 2017.

LAU, Jesús. Diretrizes sobre desenvolvimento de habilidades em informação para a aprendizagem permanente. 2008. Disponível em: https://www.ifla.org/files/assets/information-literacy/publications/iflaguidelines-pt.pdf. Acesso em: 9 jun. 2017.

LOUREIRO, Regina Célia Campagnoli. A especialidade do bibliotecário jurídico: bases para uma interação com o usuário operador do direito. $2015 . \quad$ Disponível em: http://www.egov.ufsc.br/portal/conteudo/especialidade-do-bibliotecáriojurídico-bases-para-uma-interação-com-o-usuário-operador-do. Acesso em: 9 jun. 2017.

MIRANDA, Ana Cláudia Carvalho de; D'AMORE, Ticiano Maciel; PINTO, Virginia Bentes. Gestão documental da informação jurídica. Perspectivas em Ciência da Informação, Belo Horizonte, v. 18, n. 3, p. 96-110, jul. $2013 . \quad$ Disponível em: http://portaldeperiodicos.eci.ufmg.br/index.php/pci/article/view/1710. Acesso em: 9 jun. 2017.

MOZZATO, Anelise Rebelato; GRZYBOVSKI, Denize. Análise de conteúdo como técnica de análise de dados qualitativos no campo da administração: Potencial e Desafios. 2011. Disponível em: http://www.scielo.br/pdf/rac/v15n4/a10v15n4. Acesso em: 9 jun. 2017. 
NASCIMENTO, Lúcia Maria Barbosa do; GUIMARÃES, José Augusto Chaves. A organização da informação jurídico-digital e os avanços teóricos da diplomática: uma reflexão acerca da eficácia probatória do documento. Informação \& Informação, Londrina, v. 12, n. 2, jul./dez. 2007. Disponível em:

http://www.uel.br/revistas/uel/index.php/informacao/article/view/1762.

Acesso em: 19 nov. 2018.

NEVES, Dulce Amélia de Brito; ANDRADE, Wendia Oliveira de. Usuários da informação jurídica: quem são e como funciona o fluxo informacional no âmbito do arquivo da Justiça Federal da Paraíba (JFPB). Biblionline, João Pessoa, v. 8, ed. especial, p. 55-64, jan. 2012. Disponível em: http://periodicos.ufpb.br/index.php/biblio/article/view/14190. Acesso em: 9 jun. 2017.

OLIVEIRA, Francisco Neves. Técnicas de amostragem utilizadas pelos serviços de auditoria interna de empresas no Brasil: um estudo de caso. 1989. 156 f. Dissertação (Mestrado) - Curso de Ciências Contábeis, Fundação Getúlio Vargas - Instituto Superior de Estudos Contábeis, Rio de Janeiro, $1989 . \quad$ Disponível em: http://bibliotecadigital.fgv.br/dspace/bitstream/handle/10438/9206/0000 81542.pdf Acesso em: 13 mar. 2017.

OLIVEIRA, João Nuno; AMARAL, Luís Alfredo. O papel da qualidade da informação nos sistemas de informação. In: CONFERÊNCIA ESPECIALIZADA EM SISTEMAS E TECNOLOGIAS DE INFORMAÇÃO, $1 .$, 1999, Lisboa. Comunicação oral, Lisboa: Universidade do Minho, 1999. p. 1-17. Disponível

em: https://repositorium.sdum.uminho.pt/bitstream/1822/2183/1/O papel da qualidade da informação nos sistemas de informação - completo.pdf. Acesso em: 9 jun. 2017.

PASOLD, Cesar Luiz. Metodologia da pesquisa jurídica: teoria e prática. 13. ed. Florianópolis: Editora Conceito, 2015. 232 p.

PASSOS, Edilenice. O controle da informação jurídica no Brasil: a contribuição do Senado Federal. Ciência da Informação, Brasília, v. 23, n. 3, p. 363-368, set./dez. 1994.

PASSOS, Edilenice. Bibliotecário Jurídico: mapeamento de sua produção bibliográfica. In: PASSOS, Edilenice (Org.). Informação jurídica: teoria e prática. Brasília: Thesaurus, 2004. Cap. 8. p. 189-200.

PASSOS, Edilenice. O Futuro da Biblioteca Jurídica. Infolegis, Brasília, v. 2, n. 2, p.12-43, maio 2005. Disponível em: http://www.infolegis.com.br/wa_files/futuro-biblioteca-juridica.pdf. Acesso em: 09 jun. 2017.

PASSOS, Edilenice; BARROS, Lucivaldo Vasconcelos. Fontes de informação para pesquisa em direito. Brasília: Briquet de Lemos, 2009. 170 p.

ROSA, Regina Célia; CRIVELLARI, Helena Maria Tarchi. Caracterização do trabalho bibliotecário no campo jurídico em Belo Horizonte. In: 
ENCONTRO NACIONAL DE PESQUISA EM CIÊNCIA DA INFORMAÇÃO, 8., 2007, Salvador. Anais [...] Salvador: Enancib, 2007. p. 1-14. Disponível em: http://www.enancib.ppgci.ufba.br/artigos/GT6--241.pdf. Acesso em: 9 jun. 2017.

SENA, Alexandre; PIRES, Erik André de Nazaré. Qualidade da informação: uma breve abordagem sobre a contribuição do periódico científico para ciência. Múltiplos olhares em ciência da informação, Pará, v. 2, n. 1, p.119, mar. 2012. Disponível em: http://portaldeperiodicos.eci.ufmg.br/index.php/moci/article/download/15 39/1133. Acesso em: 9 jun. 2017.

TORRES, Simone. A caracterização do documento jurídico para a organização da informação. 2013. 180f. Dissertação (Mestrado em Ciências da Informação) - Escola de Ciência da Informação, Universidade Federal de Minas Gerais, Belo Horizonte, 2013. Disponível em: http://www.bibliotecadigital.ufmg.br/dspace/bitstream/handle/1843/ECIC -9CAHBP/disserta_o__simone_torres__texto_final.pdf?sequence $=1$. Acesso em: 19 nov. 2018.

VITORIANO, Élen Rafael. Normas e Legislação de Documentos Jurídicos. Brasília: Faculdade Unyleya, 2018. 67 p. Disponível em: http://moodle.posavm.com.br/pluginfile.php/2116124/mod_resource/cont ent/11/Normas\%20e\%20Legisla\%C3\%A7\%C3\%A30\%20de\%20Document os\%20Jur\%C3\%ADdicos\%20-\%20final.pdf. Acesso em: 21 nov. 2018.

ZANETTI, Robson. A internet em benefício do acesso à informação jurídica. 2003.2 Disponível em: http://www.buscalegis.ufsc. br/revistas/files/anexos/6454-6454-1-PB.pdf. Acesso em: 9 jun. 2017. 